\title{
A CULTURA ACIMA dE TUDO?
}

\author{
VIDAPÚBLICAEIDENTIDADENACIONAL. LEITURASBRASILEIRAS
}

de Adrián Gurza Lavalle. São Paulo: Globo, 2004.

EVELINA DAGNINO

O livro de Adrián Gurza Lavalle é uma análise cuidadosa e provocativa dos modos de pensar o espaço público empregados pela tradição das ciências sociais brasileiras. Embora a análise se concentre nas idéias sobre o assunto que vieram à luz em meio à intensa vitalidade intelectual que o país experimentou na década de 1930, ela alcança também tanto o século XIX como as versões mais contemporâneas do tema. Assim, ao lado de autores como Gilberto Freyre e Sérgio Buarque de Holanda e vários de seus contemporâneos, vamos também encontrar Roberto DaMatta, José de Souza Martins, Marilena Chauí, Vera da Silva Telles, Guillermo O'Donnell e outros.

Recobrindo esse amplo cenário, a análise opera em dois registros, o dos conteúdos substantivos das idéias formuladas sobre os temas da vida pública e da identidade nacional, e o dos procedimentos analíticos utilizados nessa formulação. É ao privilegiar este segundo registro que o esforço do autor assume uma característica distintiva e original no já volumoso conjunto de estudos dedicados aos pensadores do Brasil. Assim, o argumento central que articula esses dois registros é a reconstituição de um ethos público, cuja lógica própria marcaria fundamentalmente as concepções analisadas. Mas se engana o leitor que espera, no desenvolvimento desse argumento, percorrer uma estrada linear e direta. Inúmeros desvios, curvas e pontes o esperam. São eles que, outra vez, distinguem este trabalho de outros, seus paralelos, e o tornam um rico repertório de pistas e indicações sugestivas, tanto de ordem substantiva como epistemológica.

A referência central a um ethos público anuncia já o que parece ser o alvo principal da crítica do autor às concepções que examina: a sua determinação fundamental viria da esfera da cultura, de um conjunto de valores e percepções que, engendrados na vida privada, se transfeririam para a vida pública, impondo a esta uma configuração particular, que, por sua vez, caracterizaria a natureza do espaço público que se constitui no Brasil. Nesta configuração se alinham 
elementos conhecidos, que vão desde a rarefação da vida social e a existência de uma sociabilidade incivilizada até as várias manifestações do privatismo. Cuidadosamente resgatados pelo autor, a partir de uma multiplicidade de referências, eles compõem, sob um vocabulário diferenciado e ênfases distintas, um diagnóstico recorrente na sua negatividade. Assim, o ethos público aparece, desde logo, como um pathos: as deficiências da vida social presidida por essa matriz cultural pervertem a existência da vida pública, obstaculizando, portanto, a constituição de um genuíno espaço público.

Presidida pela primazia atribuída à dimensão cultural, essa análise está vinculada de forma inextricável à identidade nacional e a ela se subordina. Mas é apenas quando, a partir de 1930, as formulações desta problemática se afastam progressivamente dos modelos explicativos de base naturalista e biologicista, com suas conhecidas implicações raciais, e a submetem a determinações culturais, psicológicas ou econômicas, que se poderia propriamente falar de um ethos público. Nesse sentido, a afirmação do "estatuto basal da cultura" (p. 136), ao confrontar os determinismos então vigentes, tem, então, um significado inovador. Com isso, ao mesmo tempo, o autor alerta para o equívoco de privilegiar a continuidade histórica de certos temas, ignorando a descontinuidade entre os horizontes de problemas, que impõem reapropriações específicas desses temas a fundar novas abordagens analíticas.

Gurza Lavalle apresenta a reconstituição do ethos público e seus principais argumentos à moda de uma rapsódia, analogia autorizada "graças ao fato de as variações se reportarem ao mesmo núcleo conceitual de forma não contraditória, operando uma contínua reposição de argumentos por caminhos não muito diversos e, por vezes, bastante parecidos" (p. 101). É sob esta chave que são então examinados os vários autores que, ao longo dos anos 1930, nas suas similaridades e diferenças, gravitam em torno do núcleo básico da transposição do privado no público, derivado da identidade nacional. O esforço é, sem dúvida, bem-sucedido. Mas os acordes dissonantes, cuidadosamente registrados, é verdade, apontam caminhos que poderiam talvez levar água a outros moinhos. Examinadas detidamente pelo autor, as diferenças entre Gilberto Freyre e Sérgio Buarque de Holanda (mais a posição ambivalente de Nestor Duarte) quanto às possibilidades de extinção do ethos público pela ação transformadora de forças modernizantes, como, por exemplo, a progressiva incorporação dos trabalhadores à vida política, poderiam também ser lidas como diferenças em relação ao próprio estatuto conferido à determinação cultural pelos diferentes autores. Assim, em Sérgio Buarque de Holanda, o reconhecimento de determinações externas à cultura, capazes de transformá-la, parece confrontar a idéia da primazia da cultura. Dada a centralidade que ocupa a determinação cultural na configuração do ethos público, essas divergências poderiam ser interpretadas como atonalidades, que escapariam então à harmonia da rapsódia. 
A discussão da reprodução do ethos público no pensamento contemporâneo ocupa a última parte do livro. Desacreditada a sua âncora básica, a identidade nacional, a sobrevivência desse modelo explicativo se ampararia na manutenção do "pressuposto lógico da existência de uma identidade cultural maior", e na redução do ethos a um "expediente explicativo ad hoc" (p. 136). Nessa nova condição, ele continuaria a ser convocado para explicar as perversidades e insuficiências do nosso espaço público, tal como parte das teses consolidadas pela literatura dos anos 1930, "agora flexibilizadas pela destituição da cultura como determinação fundamental” (p. 138). Marcada freqüentemente pela ambigüidade e até pela contradição, a utilização desse expediente é variável, expressando-se às vezes na forma de simples argumento ocasional mas também como "interpretação afirmativa". Mais, "a denúncia de todos ou de algum desses traços negativos não necessariamente implica a incorporação do ethos como expediente explicativo, podendo decorrer de outros pressupostos analíticos" (p. 140). Aqui não é o caso, portanto, de invocar a analogia da rapsódia; pelo contrário, as diferenças são reconhecidas como fronteiras entre distintos campos analíticos no tratamento de uma problemática - a do espaço público - que permanece, não obstante, um terreno escorregadio e altamente sujeito a cair no culturalismo e na reposição da lógica do ethos.

Para o autor o caso mais notório da "interpretação afirmativa" contemporânea do ethos público é o conhecido diagnóstico do dilema brasileiro de Roberto DaMatta. Reivindicando para parte de sua obra o caráter de herdeira de Sérgio Buarque e Gilberto Freyre, DaMatta, de fato, iria além de Freyre: enquanto este "confia no desempenho da lei como constituição progressiva de um âmbito resguardado das influências do ethos, consolidando a lógica abstrata da rua", para seu herdeiro, "a lei não apenas não escapa ao controle do mundo privado, mas torna-se expediente de reposição perpétua do ethos, fechando uma espécie de círculo perverso". (p. 147).

O que explicaria a larga disseminação e a reprodução tão persistente do ethos público, seja como argumento pontual, já esvaziado do seu vínculo original à identidade nacional, seja como fundamento analítico que a preserva? O que para outros poderia passar como um índice legitimador do seu poder enquanto categoria analítica, aponta, para Gurza Lavalle, para sua força enquanto representação. Distinta do conhecimento, que exige a demonstração de suas condições de validez, a representação "preocupa-se fundamentalmente com a 'necessidade' de sentido [...] conferindo direção mais ou menos unívoca e homogênea aos acontecimentos" (p. 149). Para isso, dispõe de recursos alheios à historiografia como conhecimento; entre eles, a "simplicidade" e a "beleza" subjazem à sedução e à internalização do ethos público pelo senso comum. Ao lado da "beleza" ou "contundência estilística" incorporada à representação do ethos, o seu nível de abstração, generalização 
e abrangência produziriam um efeito de convencimento na própria medida em que funcionam como simplificadores, eliminando particularidades e condicionantes. Além disso, "o ethos ainda é passível de invocação como hipótese ad hoc sem causar estranhamento” devido à "cristalização e larga aceitação de (auto) representações acerca da sociabilidade incivil imperante no país" (p. 152).

Consciente dos limites dessa explicação sobre a permanência do ethos, o autor encerra o livro retomando, agora de forma mais sistemática, a crítica aos "riscos e distorções presentes na lógica do ethos público". Não se trata aqui, para ele, de demonstrar o caráter "não científico" ou "falso" das formulações presididas pelo ethos, mas de examinar como operam os "obstáculos epistemológicos" que elas constroem: "as armadilhas do ethos podem ser concebidas como barreiras de pensamento contra o próprio pensamento". São elas o "raciocínio tautológico" e a "definição pela ausência ou pela anomalia" (p. 156). No primeiro procedimento, as razões explicativas propostas são já parte dos atributos que definem o ethos, o raciocínio se torna circular, produz-se a explicação mas não a compreensão. Essa distinção, crucial para a argumentação do autor e apenas referida antes, é, infelizmente, reduzida a uma nota de rodapé, em que a compreensão é vinculada ao esforço de problematização, para o qual "é preciso renunciar, no primeiro momento, à tentação de explicar" (p. 205). Ademais, por instigante e rica que essa distinção se anuncie, a questão aqui pareceria estar antes na qualidade da explicação que um raciocínio desse tipo pode produzir.

Por meio do segundo procedimento, a configuração do espaço público é construída em negativo: "como afirmação daquilo que não é ou como negação do que deveria ser", numa "lógica da anomalia". O resultado seria o obscurecimento de sua especificidade. Aqui, curiosamente, Gurza Lavalle é econômico no registro daquilo que, de fato, pareceria a razão mais importante subjacente a este procedimento que, de resto, tem larga tradição no pensamento crítico. Assim, mais que a constatação do forte elemento normativo presente nas análises não apenas da configuração do espaço público, mas também nas de temas correlatos como cidadania e a própria democracia, marcadas por uma significativa contigüidade com o debate político, a análise das suas implicações certamente mereceria maior desenvolvimento. Poderia sugerir, por exemplo, que o "alto contraste" produzido por esse tipo de análise não é necessariamente uma conseqüência inesperada, derivada de um equívoco metodológico, mas um resultado intencional, que é também político, no esforço de acirrar a diferença entre o que é e o que deveria ser. Ganha-se em identificar de modo incisivo aquilo que é considerado como o terreno específico dos desafios e da disputa pela construção do que deveria ser. No âmbito do debate propriamente teórico, afirma-se, contra outras concepções, concentradas na "engenharia institucional” como projeto de construção democrática, a 
importância crucial do terreno da cultura e das matrizes que a presidem. Perde-se, sim, a complexidade na análise desse terreno, no reconhecimento adequado da sua heterogeneidade e da existência de elementos que contradizem e confrontam as matrizes predominantes. Ainda estão por ser produzidas as análises que corresponderiam ao momento de síntese nesse debate, que, além de refinar a compreensão da diversidade da cultura, sejam capazes de reconhecer e integrar as várias dimensões que seguramente incidem na configuração do espaço público.

O precário reconhecimento do peso das intenções político-normativas e do caráter antitético, de debate, dos textos contemporâneos que examina acaba ainda por levar o autor a algumas interpretações pontuais que parecem desfocadas, resvalando no seu alvo. As idéias de "incivilidade" e de "sociabilidade incompleta" (porque incapaz de constituir alteridade), exploradas na obra de Vera da Silva Telles, são criticadas logicamente, como contra-sensos, já que não seria possível falar de uma ausência de civilidade em sociedades complexas, ou de uma sociabilidade sem um outro. A formulação dessas idéias em Telles, por generalizantes e homogeneizadoras que sejam, não deixa nenhuma dúvida sobre seu significado e propósito: a crítica a formas específicas de sociabilidade caracterizadas pela ausência de padrões normativos fundados no reconhecimento do outro como portador de direitos, tal como citada antes pelo próprio autor. A idéia da indistinção entre público e privado, por sua vez, é criticada não só pela sua impossibilidade lógica como pela sua incompatibilidade com a realidade empírica, um critério inusitado na argumentação do autor até então: "Se existe uma forma sistemática de relacionamento com e na vida pública, não cabe afirmar a indistinção como traço definidor, tanto porque ninguém parece agir no espaço privado como se estivesse no público, quanto porque parece existir de fato uma distinção na medida em que há um padrão de conduta generalizado para quem atua dentro dos confins desse último." (p. 160). Em que pese, mais uma vez, seu caráter generalizante e indiscriminado, o significado dessa idéia, nas várias formulações que encontra em diversos autores, apesar da possibilidade de uma leitura literal do termo indistinção, se refere claramente ao argumento de que esse padrão de conduta generalizado no público seria presidido por normas e valores transferidos do âmbito privado. O fato de atuarem no público, portanto, não os converteria em normas efetivamente públicas, como parece argumentar o autor. O que aqui se ilumina com clareza é a exigência normativa, e não empírica, na definição do que é público. Quanto à afirmação - empírica - de que ninguém parece agir no privado como se estivesse no público, que constituiria a contraprova da indistinção, as invasões da autoridade pública policial nas casas da periferia pobre, para citar apenas um exemplo, não seriam manifestações de como o que passa por público, na precariedade de sua constituição, atua no âmbito privado? 
Ainda na mesma direção, para o autor, a "disposição estrutural dessas anomalias solaparia de forma sistemática as possibilidades de constituição de um espaço público efetivamente moderno" (p. 158). Essa afirmação generalizante seguramente não faz justiça a vários dos autores contemporâneos citados, ou a consideração de suas intenções político-normativas seria totalmente descabida. Para ficar nos exemplos citados acima, a precariedade da cidadania, agravada pela crescente eliminação de direitos, constitui, para Vera da Silva Telles, a base da sociabilidade incivil que vivemos. É portanto na existência plena dessa cidadania que repousaria a transformação dessa forma de sociabilidade por outras formas, mais condizentes com a configuração de um espaço público moderno.

O livro de Adrián Gurza Lavalle deverá se tornar referência obrigatória no debate sobre a configuração da dimensão pública na sociedade brasileira e, sobretudo, sobre as maneiras de pensar o papel da cultura nessa configuração. E o livro certamente merecerá esse estatuto, que só virá fazer justiça a uma reflexão cuidadosa, produzida por um pensamento erudito e sofisticado e que, sobretudo, coloca exigências incontornáveis àqueles que estão empenhados nesse debate. A reflexão séria sobre essas exigências só poderá contribuir para que o avanço desse debate nos ajude a dar conta da tarefa, teórica e política, que temos pela frente.

Evelina Dagnino é professora do Departamento de Ciência Política da Unicamp. 